\title{
Influence of Augmented Reality (AR) Technology via Mobile Application for Knowledge Transfer Program in Fourth Industrial Revolution Era
}

\author{
Seng Yue Wong \\ Centre for Internship Training and Academic enrichment (CITrA), University of Malaya, Malaysia, \\ wongsengyue@um.edu.my \\ Zuraidah Abdullah \\ Faculty of Education, University of Malaya, Malaysia
}

See next page for additional authors

Follow this and additional works at: https://scholarhub.ui.ac.id/ajce

Part of the Educational Technology Commons, and the Online and Distance Education Commons

\section{Recommended Citation}

Wong, Seng Yue; Abdullah, Zuraidah; Haq Hussin, Muhamad Saiful; Kadri, Nahrizul Adib; Obaidellah, Unaizah; and Mohd Zubir, Nashrul (2021). Influence of Augmented Reality (AR) Technology via Mobile Application for Knowledge Transfer Program in Fourth Industrial Revolution Era. ASEAN Journal of Community Engagement, 5(1), 130-153.

Available at: https://doi.org/10.7454/ajce.v5i1.1123

Creative Commons License

(c) (i) ()

This work is licensed under a Creative Commons Attribution-Share Alike 4.0 License.

This Research Article is brought to you for free and open access by the Universitas Indonesia at ASEAN Journal of Community Engagement. It has been accepted for inclusion in ASEAN Journal of Community Engagement. 


\title{
Influence of Augmented Reality (AR) Technology via Mobile Application for Knowledge Transfer Program in Fourth Industrial Revolution Era
}

\author{
Seng Yue Wong ${ }^{*}$, Zuraidah Abdullah², Muhammad Saiful Haq Hussin ${ }^{3}$, \\ Nahrizul Adib Kadri ${ }^{4}$, Unaizah Hanum Obaidellah ${ }^{5}$, Mohd Nashrul Mohd \\ Zubir $^{4}$
}

${ }^{1}$ Centre for Internship Training and Academic enrichment (CITrA), University of Malaya, Malaysia

${ }^{2}$ Faculty of Education, University of Malaya, Malaysia

${ }^{3}$ Academy of Malay Studies, University of Malaya, Malaysia

${ }^{4}$ Faculty of Engineering, University of Malaya, Malaysia

${ }^{5}$ Faculty of Computer Science \& IT, University of Malaya, Malaysia

*Correspondence email: wongsengyue@um.edu.my

Received: November $17^{\text {th }}, 2020$, Accepted: July $25^{\text {th }}, 2021$

Abstract Education is considered one of the impact sectors, which is a part of the Industrial Revolution 4.0 (IR4.0), where humanity and technology are aligned to empower new possibilities. Academic exploration of Augmented Reality (AR) technology and skills of IR 4.0 in schools, especially in rural areas, have been scarce. Therefore, this paper examines the influence of AR technology via mobile application on teachers and students via community-based learning approach. One rural primary school was selected for this community-based research project: Sekolah Kebangsaan Pulau Gaya in Kota Kinabalu, Sabah, Malaysia. It was selected as the school's drop-out rates have remained high and it has low student retention levels. Students here are unprepared for becoming more autonomous learners with better responsibility for organizing and planning their learning time. There were 22 teachers and 95 primary students ( 75 female and 20 male), aged from nine to twelve, third to sixth grades involved in this project. Their changes in attitude, practices, and skills were evaluated before and after the AR intervention. A majority showed an increase in positive preferences and enjoyment in AR learning, and in general, an increase in their STEM skills and performance. The findings show that employing an AR approach in primary students learning reveal significant differences in students' preference in AR learning, enjoyment in AR learning, performance in STEM learning, enjoyment in science learning, willingness to attend STEM classes, and STEM skills after the AR intervention. Thus, the newly developed AR learning module is an attempt to assist teachers nurture their students via this knowledge transfer program, increase their engagement, peer interactions and collaboration, and improve their confidence to become successful learners in the future.

Keywords: Augmented Reality (AR); AR Learning Module; Mobile Application; Knowledge Transfer; Fourth Industrial Revolution. 


\section{Introduction}

Education is considered one of the impact sectors, which is a part of the Industrial Revolution 4.0 (IR4.0), where humanity and technology are aligned to empower new possibilities. The advancement of technologies persists, transforming old teaching methods and setting conventional learning processes (Dunwill, 2016). Indeed, many countries have launched multiple strategies and initiatives, including educational transformation plans, redesigning and rethinking educational systems to improve the quality (and equity) of education in the new era of IR4.0. Teachers, in turn, now act as facilitators in the educational system with collaboration and social networking, as well as project- and inquiry-based learning. In this framework, positive reinforcements are utilized to promote positive learning experiences and empower students' learning and increase their confidence in their overall academic abilities (Hussin, 2018). For instance, in such cases, students are expected to explore more "real" and "handson" activities through different mentoring programs (mentor-mentee programs) (Kanchewa et al., 2021), collaborative projects, and translational and knowledge transfer programs.

\#WeAlsoHaveDreams was a project that covered academia and society with the aim to transfer necessary knowledge and skills to those who needed them the most, i.e., students, teachers, academics, and communities from diverse backgrounds, via a community-based learning approach. Our current project is similar that was conducted to address the issue of decreasing basic literacy skills of students, enhancing knowledge absorption capabilities, and empowering teachers' strategies and skills. It aims at promoting learning community among teachers and students, which encourage knowledge sharing through knowledge transfer programs (Cheng, 2020) or community-based training (Sumaryanta, Mardapi, Sugiman, \& Herawan, 2019). Hence, it is centered on community-based learning approach which is here regarded as a participatory learning process to facilitate more engagement and enrolment in creating positive attitudes toward community development, with the aim of providing new skills and knowledge for all learners (Cheng, 2020). To take a relevant example in this context, the knowledge transfer program (KTP) is a scheme designed by the Ministry of Education in Malaysia, which has enabled higher education institutions in the country to apply their expertise and scientific knowledge to different communities (Firdaus, Mohamad, Mohammad, \& Gunaratne, 2020).

Communities, in turn, have the chance to improve their living standards via these valuable inputs of innovative knowledge whereas academics from higher education institutions can maximize their innovative research and design though KTP (Wang et al., 2020). KTP could be considered a vital indicator for educational success, which could enable knowledge and skills 
that learned from the schools and applied them in a new situation. There is another term for this kind of program, i.e., service learning, which combines academic learning and community service, with the aim of promoting students' knowledge transfer. At the same it, it applies the knowledge and skills that have been learned in the classrooms to real-life contexts and situations (Wang et al., 2020).

Augmented Reality (AR) has been perceived as the new teaching tool in Malaysia. Similar to mobile applications, it has modernized learning processes and brought them closer to reallife practices. Perhaps, most importantly, it has engaged learners and allowed training to take place in more realistic learning environments (Vosinakis, Anastassakis, \& Koutsabasis, 2018; Zhu, Sun, \& Luo, 2018). Former research shows that AR learning has the potential and advantages of augmentation for teaching and learning environments, such as engaging and motivating learners to explore classes from very different viewpoints, fostering student creativity and imagination, and indicating improvement in learning outcomes (Alalwan et al., 2020). In short, AR with mobile applications has modernized the country's learning processes, brought them closer to real practices, engaged learners, and more generally, allowed training to take place in more realistic learning milieux.

AR has been experimentally adopted in education and training sectors (Alalwan et al., 2020; Arici, Yildirim, Caliklar, \& Yilmaz, 2019; Hincapie et al., 2021). It appears more advanced and powerful when being integrated into education and training, for it is more feasible in various types of devices or tools, including wireless mobile devices, such as smart phones and tablets. In the scholar's critical reviews and analysis, almost one third of the AR studies integrated design elements from game-based learning and simulation, and a third from experiential learning (Sommerauer \& Müller, 2018). The existing study also employed AR in teaching for second grade students in reference to transportation and different types of animals by superimposing 3D models or objects. Students spent some time in learning this knowledge by playing digital games (Tang, 2021). In effect, AR game is found to have assisted students familiarize with their learning spaces, objects of learning via the gameplay of the AR-and immersive AR experience (Tang, 2021). This study also indicates that AR-based learning tool can help increase students' motivation and have a positive influence on their learning experience.

As mentioned previously, in many ways, the explosion of IR4.0 has already changed the future of learning (Hussin, 2018). Indeed, AR could be considered as one of the tools that is utilized to transform the educational process into new technological-based learning methods or so-called smart-level educational tools. One of the IR4.0 requirements is the development of 
human capital to fulfill the needs of related knowledge and professions. In addition, knowledge exchange program is needed to develop new smart teaching skills (Hussin, 2018). Moreover, AR is deemed as a crucial technology for the IR4.0 approach, which itself promotes humancentric industrial environment, and thereby, allows people to access the digital world via the layer of information, which is placed on top of the physical world, such as maintenance processes, visualization technology, marker-based tracking system, and two-way communication (Masood \& Egger, 2019).

These technologies are important for educational purposes. Yet, exploration of IR 4.0 technology and skills in schools, especially in rural areas, are scarce. The awareness of IR 4.0 components and knowledge remain low among the students. Static and "boring" features of learning or co-curriculum activities in schools also contribute to the urge to explore new technologies or co-curriculum activities. Therefore, this project is aimed at embedding AR concept in conducting school learning activities and contribute to the knowledge transfer between universities and communities. At the same time, school learning or co-curriculum activities can be improved by embedding the AR technology, which is aligned with the IR 4.0. The Ministry of Education in Malaysia has also launched campaigns with other related organizations with the initiative to utilize technology to increase teaching and learning, and by that, produce first class human capital in the country.

This translational project is covered under the \#WeAlsoHaveDreams project, which is in turn aimed to transfer knowledge from the higher educational institutions to the primary schools via integrating AR technology in the instructional process in schools. The main objective of the \#WeAlsoHaveDreams project is to bridge different educational institutions, as well as educators and stakeholders, and to identify local community issues. Furthermore, the aim is to develop appropriate educational modules, which would increase the basic literacy skills of students, to train and strengthen their basic literacy skills and knowledge in addressing their own needs, and to evaluate the changes of the students toward positive improvements of their existing skills. This paper goes to present some of the findings derived from the students' perception analysis regarding their preferences and enjoyment in AR learning. We then evaluate their performance and skills before and after exploring AR learning. Finally, we present the enhanced AR learning module for teachers. Against this background, the following three research questions are examined:

1) What are the students' preferences and enjoyment in AR learning, performance, and skills before and after exploring AR learning? 
2) Are there any major differences in their preferences and enjoyment in AR learning, performance, and skills before and after exploring AR learning?

3) What is the successful design and development of an enhanced AR learning module?

\section{Methods}

This project employed a mentor-mentee program, implying that a mentor provides support, knowledge, and guidance to a mentee who then receives this guidance to increase his or her knowledge and skills. The mentoring program was selected as it is considered suitable for knowledge transmission. Moreover, it involves a sustainable relationship between a person (mentor) perceived as having more experience and knowledge, and a person (mentee) perceived as having less experience and knowledge (Zanchetta et al., 2017). The collaborative mentoring process has been proved to be significant when it comes to academic outcomes (Zanchetta et al., 2017). Mentors and mentees were motivated by their intellectual relationships; via combined situations, self-reflections, and sharing ideas and knowledge in general. The uniqueness of this collaborative relationship derives from the fact that the mentees can take responsibility through the encouragement, motivation, guidance, and examples as presented by the mentor (Lee, Krauss, Suandi, \& Hamzah, 2016). This project thereby builds a relationship, which involves more experienced people to assist the less experienced, to determine and attain their objectives based on encouragement, openness, trust, respect, and willingness to learn and share. All these factors, via the community engagement project, are pivotal and play their own vital role in achieving the goals, such mastering basic literacy skills and everyone having their own opportunities.

At the first stage, university lecturers act as mentors. They implement the training of trainer workshops to train schoolteachers (as mentees). They introduce the AR concepts with the mobile application, and the related multimedia techniques, such as text, graphic, audio, and video elements for the future teaching and learning in the schools. Figure 1 shows the snapshot of the training workshop. The new AR learning module, i.e., "Create Your Own First Augmented Reality with Vuforia," has been produced and enhanced to be used as the material to assist teachers to build their own simple AR learning experience for students. This project used mentor-mentee program, which means mentor provides support, knowledge, and guidance to the mentee receives this guidance to increase their knowledge and skills. For this AR learning module, Vuforia Engine, Unity, 3D Paint, humanoid 3D model, and Google Play were the software applications that were used to develop a simple AR for student learning. In total, there were eight modules that were developed for the simple AR learning for teachers and students. 
These eight modules, in turn, provided guidance, manual settings, steps, and tips for schoolteachers to develop simple AR learning for different school subjects.

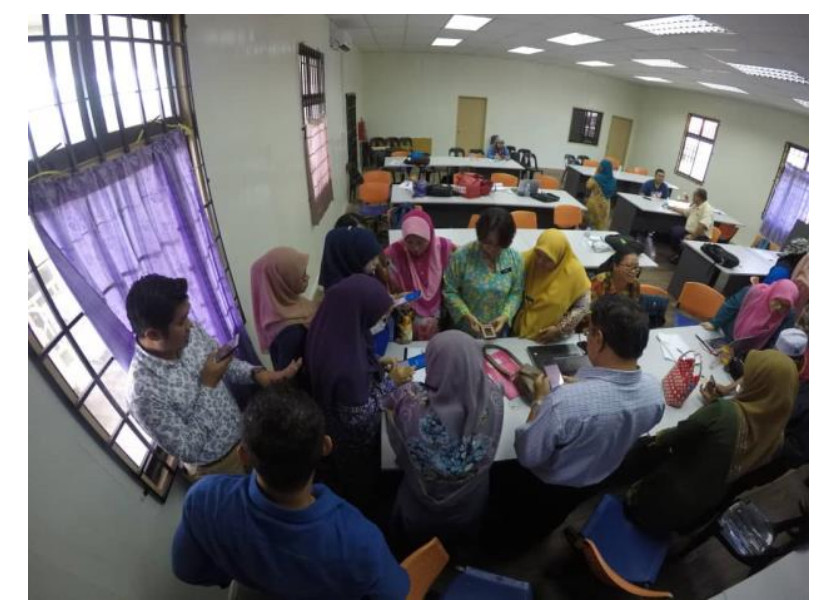

Figure 1. Training of Trainer workshop for the schoolteachers

Next, schoolteachers became mentors and taught their students AR technology, which they had learned from the workshop by using the AR module. Figure 2 shows the AR learning intervention session between schoolteachers and students. By embedding AR-based learning activity, teachers were able to engage their students to their teaching and learning process, change their attitudes toward learning, increase their practical work and other skills. For this AR learning modules, Vuforia Engine, Unity, 3D Paint, humanoid 3D model, and Google Play are the software and applications that need to develop a simple AR for students learning.

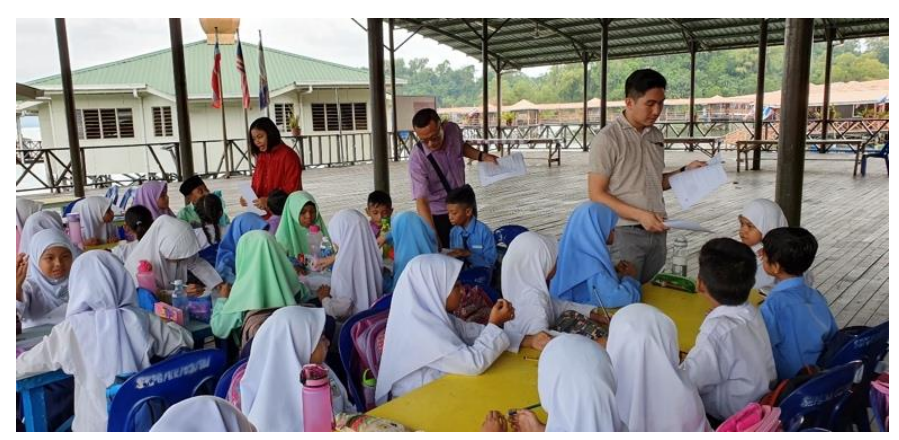

Figure 2. AR learning intervention session among the schoolteachers and students

The flow charts that describe all the project activities are illustrated in Figure 3. 


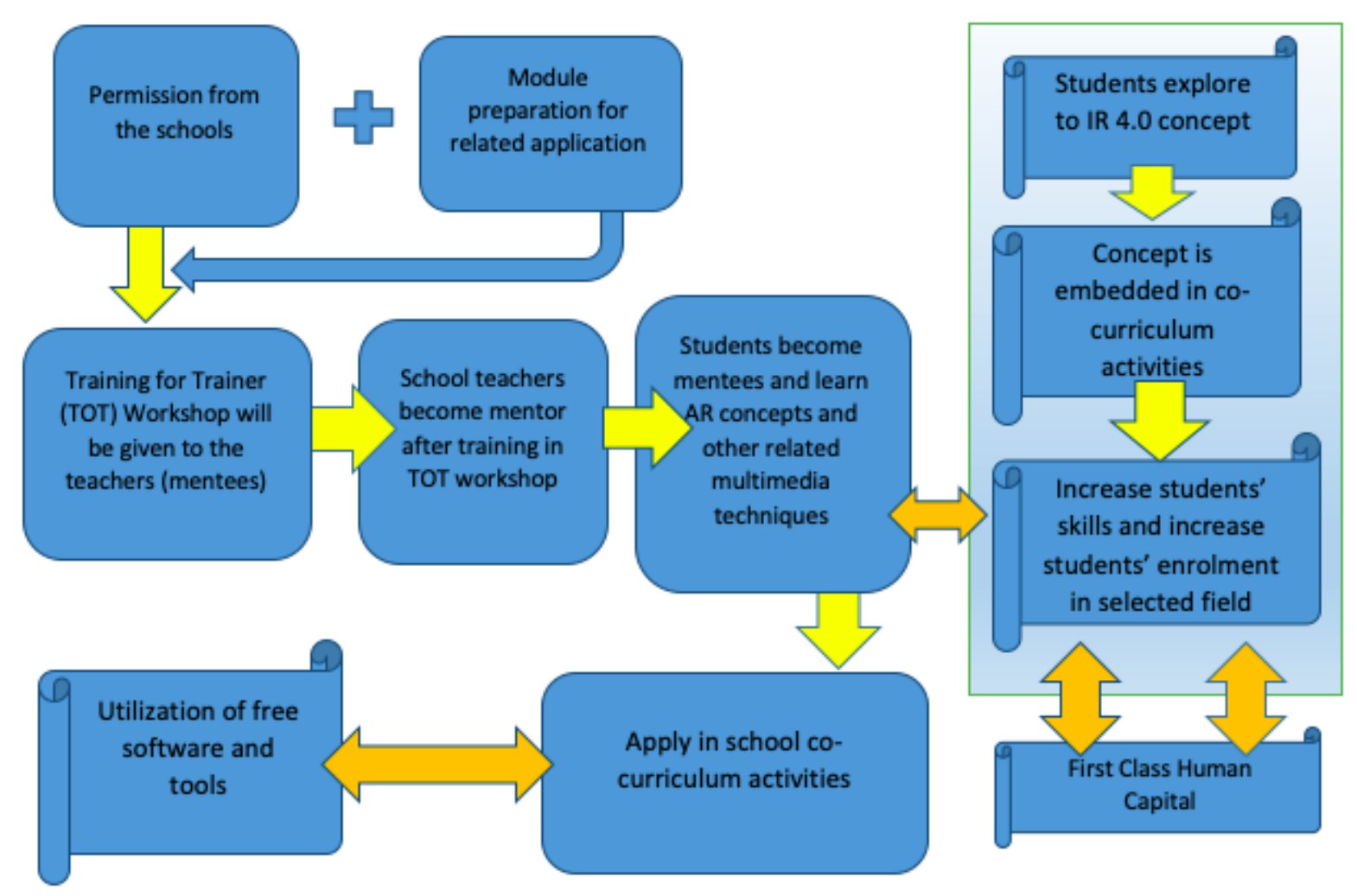

Figure 3. Flow charts for the project design

One rural primary school was selected for this community-based research project: Sekolah Kebangsaan Pulau Gaya in Kota Kinabalu, Sabah, Malaysia. The school was selected as its drop-out rates have remained high and it has low student retention rates. Students were unprepared for becoming more autonomous learners with better responsibility for organizing and structuring their learning time. As learners have positive attitudes toward AR, it has indicated improvement in learning outcomes. Thus, this project attempts at providing and exploring the application of AR technology in student learning, especially in rural areas, the aim being to get students engaged in their learning, increase their enrolment and retention rates. In the new era of IR4.0, most importantly, AR technology could engage students, and by that, increase their learning skills. Moreover, smart devices and high technology tools for rural student learning could bring many benefits when it comes to further knowledge transfer between universities and communities.

This is an exploratory case study-also called a pioneer study-where the data is collected from a small group of participants before the actual study is conducted from a large number of respondents in other schools. This study was conducted on a group of students at two different times, before and after the participation of this KTP, known as pre-test and post-test procedure. 
Availability or convenience sampling method was utilized for this exploratory case study, the aim being to find out the views and opinions of the participants regarding the effectiveness of the KTP. Altogether, in this project, there were 22 teachers and 95 primary students involved (75 female and 20 male). Students were aged from nine to twelve, i.e., from third to sixth grades. Their changes in attitude, practices, and skills were evaluated before and after AR intervention. Before the AR intervention class, the students were invited to answer some questions regarding their knowledge of AR technology and learning methods. During the AR intervention class, the students' interaction with AR tools via mobile application were observed and evaluated by their teachers. At the same time, students' responses during AR intervention class were recorded. The data was collected from 19 to 21 August 2019. Descriptive and frequency statistics were employed to further analyze the perceptions of the primary students and their demographic factors. Figure 4 presents the mapping diagram for the measurement design of the study. It shows, in particular, the impact evaluation of students' performance, engagement, skills, and practices. The research hypothesis for research question 2 (R2) is stated as detailed below:

$\mathrm{H}_{0}$ : There is no differences in the students' preferences and enjoyment in AR learning, interest, enjoyment, performance, and skills before and after exploring AR learning

$\mathrm{H}_{1}$ : There are differences in the students' preferences and enjoyment in AR learning, interest, enjoyment, performance, and skills before and after exploring AR learning

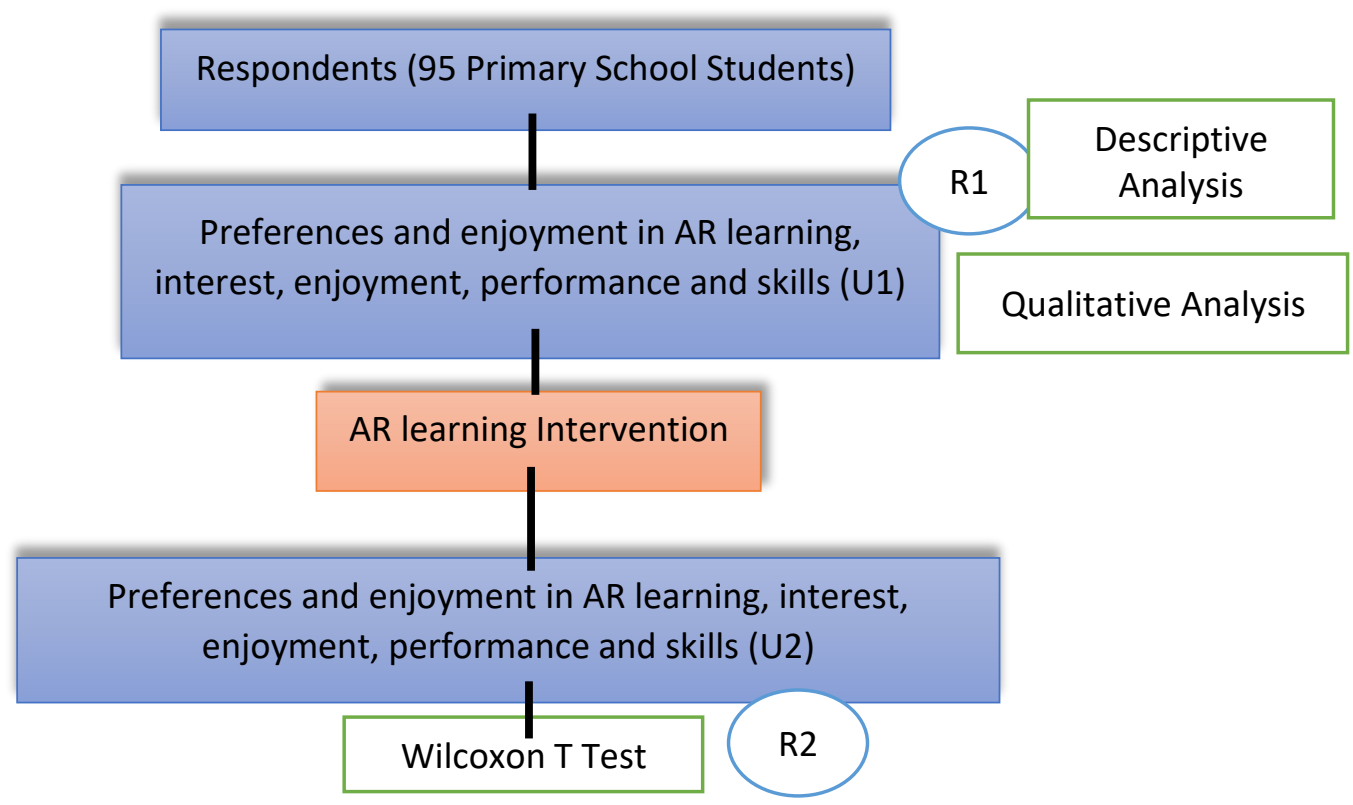

Figure 4. Mapping diagram for the research measurement design 


\section{Results and discussion}

This report presents the comparison results of primary school students' preferences, their enjoyment of AR learning, and implications of AR on their performance and skills. A majority showed an increase in positive preferences and enjoyment on AR learning and increased their skills and performance (see Figure 5). If viewed from findings in Figure 5, we can observe that the students' skills and performance increased after AR intervention. The students who perceived their skills as "good" increased from 34 to 40, whereas the students who perceived their performance as "very good" increased from 20 to 27 . In addition, there were 49 students who perceived their performance as "good" after having explored AR learning.

Furthermore, there were 47 students who enjoyed AR learning as opposed to those who did not. It is notably that only a small number of students did not enjoy (or only "sometimes" enjoyed) AR learning. The majority of students, i.e., 74, liked AR learning after being exposed to it. The data show that $78 \%$ of the students liked AR learning after intervention. Hence, the findings support earlier studies, which examined learners' positive attitudes toward learning by using AR technology (Alalwan et al., 2020; Cheng, 2017). These studies had observed that students show high educational satisfaction, perceived engagement in AR-based learning activities, positive attitudes to the usability and usefulness of AR learning systems, and behavioral intention to use AR learning tools. Thus, they consider AR learning as helpful. It increasingly attracts students' attention during the teaching and learning process.

It could be concluded that most students show a positive response to AR learning in their study, including feeling, enjoyment, performance, and skills. Schoolteachers also feel positive and motivated to teach students via AR learning tools, the aim being an increase in their students' study interests. Therefore, they are willing to build their existing AR learning tools to attract and facilitate their teaching and learning, especially for those students who really need motivation to continue their enrolment until secondary and tertiary levels. 


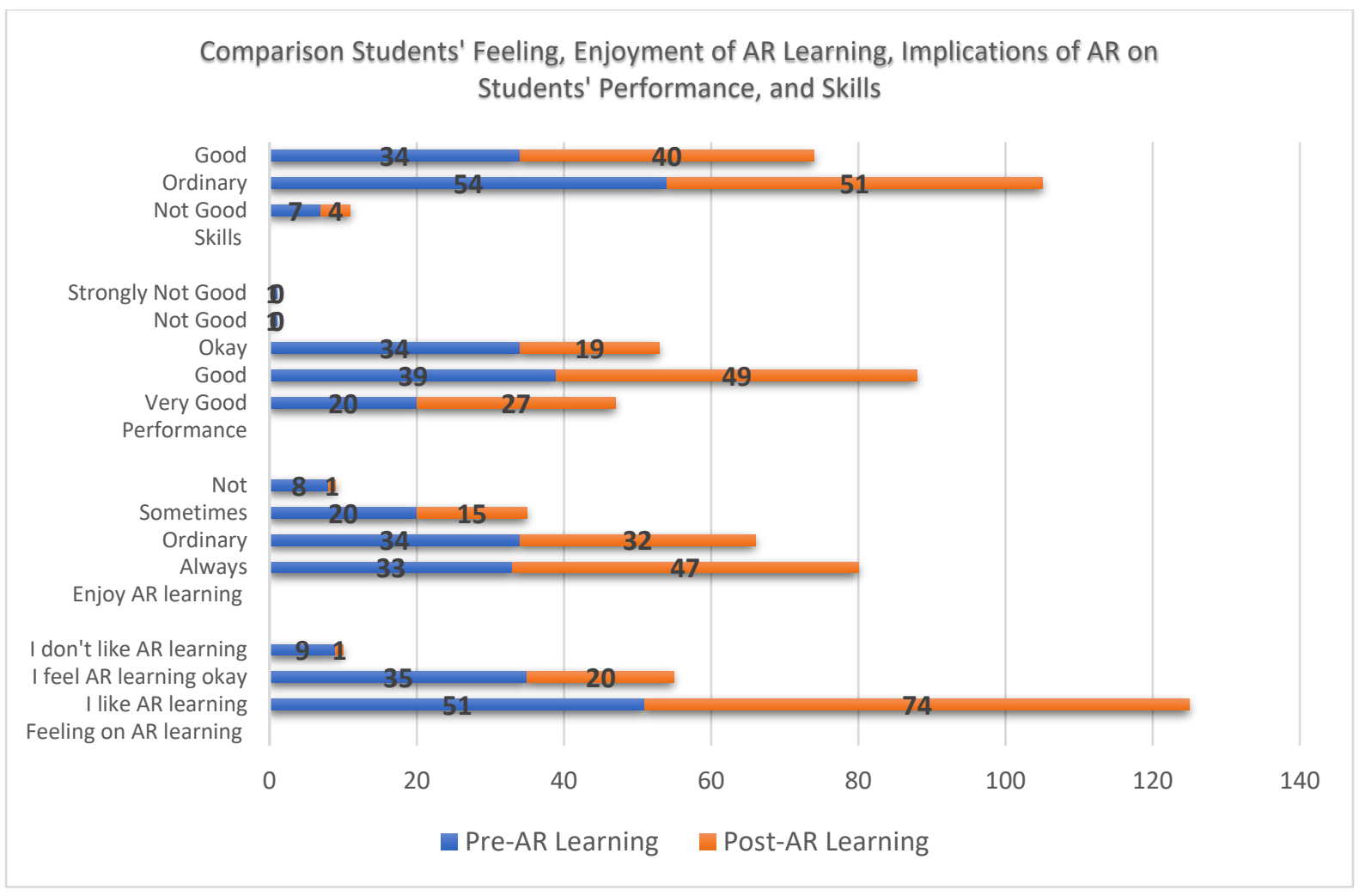

Figure 5. Comparison students' preferences, enjoyment of AR learning, implications of AR intervention on their performance, and skills

In order to answer research question 2 (R2), Wilcoxon Signed-Rank test was employed to analyze student preferences and enjoyment in AR learning, performance and skills, before and after the AR intervention. The analysis findings show that utilizing AR approach in primary students learning show significant differences in student preference in AR learning $(\mathrm{z}=-4.086$, $\mathrm{p}=.000)$, enjoyment in AR learning $(\mathrm{z}=-4.110, \mathrm{p}=.000)$, performance $(\mathrm{z}=-3.500, \mathrm{p}$ $=.000)$, and skills $(\mathrm{z}=-1.968, \mathrm{p}=.049)$ after having been exposed to AR intervention in their learning (see Table 1). Since this is an exploration study into rural primary school students, this research project should be conducted for certain longer periods of study to investigate further impacts of AR intervention on primary school students. As previously mentioned, the majority of students showed a positive attitude and responses to AR learning, this test findings are also significantly shown differences before and after AR learning intervention. These results further confirm that AR learning approach can increase student preferences, enjoyment, performance, and skills. Table 1 shows the findings of Wilcoxon test for student preferences, enjoyment, performance, and skills before and after AR learning intervention. 
Table 1. Wilcoxon T test results for students' preferences and enjoyment in AR learning, enjoyment, performance and skills before and after AR learning intervention $(\mathrm{N}=95)$

\begin{tabular}{|c|c|c|c|c|c|c|}
\hline \multirow{2}{*}{$\begin{array}{l}\text { Post-Test } \\
\text { Pre-Test }\end{array}$} & & \multirow[t]{2}{*}{$\mathrm{N}$} & \multirow{2}{*}{$\begin{array}{l}\text { Mean } \\
\text { Rank }\end{array}$} & \multirow{2}{*}{$\begin{array}{l}\text { Sum of } \\
\text { Ranks }\end{array}$} & \multirow[t]{2}{*}{$\mathrm{Z}$} & \multirow[t]{2}{*}{ P-Value } \\
\hline & & & & & & \\
\hline Preference on & Positive Ranks & $30^{\mathrm{a}}$ & 19.20 & 576.00 & -4.086 & $.000 * *$ \\
\hline AR learning & Negative Ranks & $6^{\mathrm{b}}$ & 15.00 & 90.00 & & \\
\hline \multirow[t]{2}{*}{ post-Pre- } & Ties & $59^{c}$ & & & & \\
\hline & Total & 95 & & & & \\
\hline Enjoyment in & Positive Ranks & $26^{\mathrm{a}}$ & 16.35 & 425.00 & -4.110 & $.000 * *$ \\
\hline AR learning & Negative Ranks & $4^{b}$ & 10.00 & 40.00 & & \\
\hline \multirow[t]{2}{*}{ post-Pre- } & Ties & $65^{c}$ & & & & \\
\hline & Total & 95 & & & & \\
\hline Performance & Negative Ranks & $28^{\mathrm{a}}$ & 19.21 & 538.00 & -3.500 & $.000 * *$ \\
\hline in STEM & Positive Ranks & $8^{b}$ & 16.00 & 128.00 & & \\
\hline learning post- & Ties & $59^{c}$ & & & & \\
\hline Pre- & Total & 95 & & & & \\
\hline STEM skills & Negative Ranks & $4^{\mathrm{a}}$ & 7.00 & 28.00 & -1.968 & $.049 * *$ \\
\hline \multirow[t]{3}{*}{ post-Pre- } & Positive Ranks & $11^{\mathrm{b}}$ & 8.36 & 92.00 & & \\
\hline & Ties & $80^{c}$ & & & & \\
\hline & Total & 95 & & & & \\
\hline
\end{tabular}

Next, this project was progressed to the next phase to enhance the AR learning module for schoolteachers based on their suggestions and interview findings. A new AR learning module was then designed and developed to assist teachers build their own AR learning tools. Simple video, animations on 3D object could be built via this learning module. Guidance and step-bystep training were given through the module so that teachers could learn to build new AR learning tools more easily. The newly enhanced AR learning module was named as "Create your first Augmented reality (AR) with Vuforia." In total, there were eight modules that were developed for the simple AR learning for teachers: (i) Design and develop image-based targets; (ii) Tips to design and develop image-based targets; (iii) Animation on organic 3D object; (iv) Animation on simple 3D object; (v) Video on simple 3D object; (vi) Build APK for Android; (vii) How to use the play console; and (viii) Upload AR application on Google Play. These eight modules provided the guidance, manual settings, steps, and tips to schoolteachers for 
developing simple AR for different school subjects. The following provide the descriptions and contents of these eight AR learning modules.

(i) Module 1 "Design and develop image-based Targets"

This module is about how to select a good image tracker and how to design it to become five stars in the Vuforia database. Examples of different images, natural features, and image ratings have been listed in the module. At the same time, contrast, feature distribution, organic shapes, repetitive patterns, non-rectangular image targets, and feature-exclusion buffer are also described in the module.

(ii) Module 2 "Tips to design and develop image-based targets"

This module is about how to choose an appropriate image and edit it accordingly. Here 3D paint is used to edit images.

(iii) Module 3 "Animation on organic 3D Object"

In this module, Unity 2019 and Vuforia Engine are used to create AR on an a 3D organic object. This module lists all the steps required to register an account, to find the characters and save it, to create and develop animations and save it as FBX For Unity, to prepare image targets, and set up a 3D model and animation settings.

(iv) Module 4 "Animation on 3D object"

This module is about how to apply a simple animation on a simple 3D object by using Unity 2019 and Vuforia Engine. This module consists of four steps: (i) prepare an image target, (ii) create a 3D object, (iii) set up animation and animator, and (iv) create the animation.

(v) Module 5 "Video on 3D object"

This module is aimed to teach how to apply a simple video on a simple 3D object by using Unity 2019 and Vuforia Engine. This module involves four steps: (i) prepare an image target, (ii) create a 3D object, (iii) set up a video, and (iv) set up the control button.

(vi) Module 6 "Build APK for Android"

This module is aimed to enable teachers to learn how to build an Android Application Package (APK) file for Android. The APK is used for installing and running AR on Android devices. Teachers need to prepare Unity Hub and have internet access for downloading files. This module consists of five steps: (i) preparation before start, (ii) set up scene, (iii) set the project platform, (iv) edit APK file, and (v) building APK file.

(vii) Module 7 "How to use the play console"

Before uploading applications on Google Play, it is important to learn about how to use the play console and it is the main purpose for this module. To start using the play console, there is a need to register for a Google Play Developer account. After that, a registration fee is 
charged. Then, the user can manage account information and start using the play console. All the settings and guidelines for the play console personalization are provided in this module.

(viii) Module 8 "Upload AR App on Google Play"

This module aims to train teachers to upload their built AR App on Google Play. The requirements for this module are Unity 2019, Google Play Account, AR project (completed by using Vuforia Engine), icon, some snapshots of the AR project, and a feature graphic and privacy policy. There is a template for privacy policy provided in this module for users or teachers review, which is followed by "step-by-step" tasks until a successful uploading of the AR application on Google Play has taken place.

To take a relevant example, an ordinary schoolbook can become a "magic book" when AR technology is applied to it. Students could feel excited and more motivated when they read these "magic books" in interactive and realistic ways, which is done by superimposing 3D objects or models to them by using AR technology. This way, AR could enable educational environments to be more productive, pleasurable, and interactive (Alalwan et al., 2020; Cheng, 2018). Not only does AR engage students-particularly younger ones -in multiple interactive ways to learn, but also, it provides unique discovery paths with comprehensive learning materials via 3D environments and models. If compared to prior studies (Pantelic \& Vukovac, 2017), the AR learning module is emphasized as a simplifying tool that facilitates the interaction between teachers and students. In other words, teachers design and develop their own AR tools to enhance and improve the whole teaching and learning process. In such cases, students are able to produce and receive knowledge with the aid of 3D simulations. This module also provides the opportunity to learn new skills via AR technology. It encourages students to build positive characters and minds. Moreover, this community-based learning approach is a participatory learning process to facilitate the broader participation in creating the necessary attitudes toward greater community development, which is done by offering the relevant skills and knowledge to all students.

One of the main challenges of AR-based learning utilization in teaching and learning is cost and/or expensive designs (Hincapie et al., 2021). Thus, this enhanced AR learning module is designed and developed for the simplicity to implement AR application in schoolteachers' teaching and learning plans to enhance immersion and presence among students by integrating new AR-based learning tools. The pedagogical strategies have been considered for the implementation of AR-based learning tools in the teaching and learning process. The AR-based learning tools usually involve participatory simulations, and by that, teachers are often required to shift the attention from themselves to learner-centered and inquiry-based learning. The 
ADDIE model is used to design and develop learning contents for AR applications to ensure that AR-based learning tools are pedagogically sound. Finally, teachers may need to evaluate and assess the resources that are available to ensure the suitability and appropriateness of AR learning tools for their students.

The KTP has progressed to assist and offer opportunities for students to improve their literacy skills. Different collaborators could then take up the same idea and apply the same concept to other contexts. This is one of the methods in which academia could contribute to the community as a while. Using the concept of collaborative partnership, this project has been extended to Universiti Malaysia Sabah academia, in which knowledge transfer begins at a collegial level. Learning from experts, training has been given to academics, teachers, and university student volunteers to attribute the project. Following the concept of scaffolding, mediation, and regulation in Vygotsky's sociocultural learning theory, collaborative learning offers learners more effective learning opportunities where they could learn from the community of learners through social interaction, activity engagement, as well as reflective thinking (Chang \& Hwang, 2018; Georgiou \& Kyza, 2018).

With the assistance of AR-based learning tools which consisted of 3D animation, the physical classroom practices and learning activities become more fun and interesting. This advantage further attracts students' attention and enables them to be more engaged in their learning process. In short, it motivates them to learn well. Students may gain a better understanding of selected school topics by offering them extra information through visual 3D models. Furthermore, the subject contents could be understood more easily by using AR technology. For instance, it could create objects that are hard to visualize and transform them into 3D models. Simultaneously, AR technology could also act as a friendly system that assists students with special learning needs. In addition, AR could help students with low comprehension abilities, for example, when they need more time to achieve certain learning goals, improve their confidence or complete their lessons.

\subsection{Discussion}

In one of the previous studies regarding innovation and knowledge sharing, innovation is considered as being dependent on knowledge sharing (Castaneda \& Cuellar, 2020). Knowledge sharing involves the transfer of experiences, skills, and information into different practices, where the organization often encourages knowledge sharing and facilitates innovation capabilities (Castaneda \& Cuellar, 2020). Knowledge sharing, in turn, is claimed as a key success factor that leads to innovation, which means that innovation can only take place when 
knowledge sharing is present (Kremer, Villamor, \& Aguinis, 2019). Therefore, this study has attempted to embed AR technology in school learning activities via knowledge transfer programs, for AR plays an important role in various knowledge transformation modes. Our findings indicate that the majority of the respondents show an increase in positive preferences, and enjoyment in AR learning. It has increased the students' STEM skills and performance. These findings are supported by other previous studies, which have already revealed that students can demonstrate greater educational achievement in knowledge while using AR in physics education (Yoon, Anderson, Lin, \& Elinich, 2017). This has further increased their attention to school practices, particularly with regards to pre-school education (Ozdamli \& Karagozlu, 2018), and increased their motivation and interaction as well as positively impacted their learning in general (Cheng, 2018).

Furthermore, the KTP scheme has become one of the main initiatives of some higher education institutions. The plan has been to develop knowledge assets via conducting research and development activities and transferring knowledge to the recipients (Cheng, 2020). Cheng (2020) also maintains that effective knowledge transfer strategies need to consider the absorptive capacity of knowledge recipients. Knowledge is here defined as information that can be easily transferred to others as information. AR, in its part, can transfer knowledge via placing information in explicit contents, but it also cause a limited transfer for explicit knowledge (Del Amo et al., 2018). Some scholars (Masood \& Egger, 2019) have also reported how data that are visualized make AR a powerful key technology in education. In short, it promotes "the real space" and its utilization in a complex environment of IR 4.0. With the new affordability of mobile devices, smartphones, and tablets (with all their sensor features and processing facilities), AR applications are now easy to develop and deploy (Bonner \& Reinders, 2018). Thus, our study, which has utilized AR technology in knowledge transfer programs, has contributed to community services in the sense that they have increased students' attention spans, affected their behavior positively, and raised student retention and enrolment rates, at least indirectly.

As has been put forward by previous academic research, AR has offered new insights into teaching and learning, and is currently being increasingly recognized by scholars across different disciplines. First, AR technology can increase students' motivation to study. As our results show, the majority of students, i.e., 49.5\%, always enjoy AR learning when compared to the $17.9 \%$ of students who do not enjoy it, or sometimes enjoy it. Moreover, there were significant differences in the student enjoyment before and after AR intervention. Students enjoying AR learning is supported by other academic studies in this research field, which claim 
that students are more eager to learn, and more interested and engaged to deal with new technology, such as AR, when being compared to non-AR assisted instruction (Petrov \& Atanasova, 2020). For example, AR can be utilized in an AR book form, which enables students to view 3D presentation and interactive learning experiences with the assistance of a special glass. This feature can increase their motivation and attention to learn further and continue learning by using AR technology after class. While using AR technology, students can concentrate better and remain focused in their learning as they appear more motivated to learn.

Second, students' satisfaction is increased when they feel satisfied about their learning process and educational progress. Students were satisfactory and motivated by these new AR technologies in their learning as our findings also reported that AR has increased student's preference in AR learning from 53.7\% to $77.9 \%$. AR assists students to explore real-world by illustrating the digital objects and phenomena which are hard to be observed from a text, picture and blackboard (Gomez-Galan, Vazquez-Cano, Rosa, \& Lopez-Meneses, 2020). This, in turn, implies that AR can be utilized to interpret difficult and complex situations in completely new ways when it comes to education. For instance, AR technology can incorporate immersive features into different teaching and learning processes. Students, in their part, have shown high levels of satisfaction when they are joining these learning activities. They appear more motivated toward instruction that incorporates these features, which improves their academic results (Salar, Arici, Caliklar, \& Yilmaz, 2020).

Third, AR can promote student-centered learning, which here refers to self-directed or selfpaced learning that is currently replacing conventional class teaching or teacher-centered learning. In student-centered learning, students are responsible for their own learning and progress in educational processes. Instructors, or schoolteachers, are here seen as mere class facilitators who guide students to learn independently and more individually. In this context, different mobile devices with AR applications can be adapted accordingly to fit students' needs and interests and facilitate personalized learning (Bonner \& Reinders, 2018). Therefore, this study has attempted to use AR technology to train teachers by using simple modules for AR development in education. Teachers can then go to create, design, and develop a simple AR learning tool for their students. Indeed, as part of this, AR could promote student-centered learning. It could improve students' abilities to explore and learn new knowledge, solve problems autonomously, and facilitate critical thinking and relevant communication skills (Chang \& Hwang, 2018; Hincapie et al., 2021). Teachers can combine different AR applications to reinforce flipped classroom and student-centered learning. In fact, it is now 
being used at all levels of education, from primary schools to university levels (Gomez-Galan, Vazquez-Cano, Rosa, \& Lopez-Meneses, 2020). For example, scholars have found that AR is beneficial for teaching STEM subjects, due to its features like ease of use, high level of personalization, and the possibility to run many different applications (Petrov \& Atanasova, 2020). This also supports this study's findings, which have shown that employing AR in primary student learning has shown significant differences in student preferences in AR learning, enjoyment in AR learning, performance in STEM learning, enjoyment in science learning, willingness to attend STEM classes, and STEM skills after AR intervention.

Fourth, collaborative learning can be promoted and enhanced by using AR technology. Researchers have reported that AR applications have improved collaborative learning via new ways of communication, interaction, and cooperation (Hincapie et al., 2021; Yoon et al., 2018). Moreover, AR technology has facilitated social interactivity, interaction, and collaborative learning (Bonner \& Reinders, 2018; Gomez-Galan, Vazquez-Cano, Rosa, \& Lopez-Meneses, 2020). AR is the representation of visual virtual information, which is added to the real-world environment. Thus, students can access rich, diverse, and meaningful multimedia contents to learn, offering them related materials they can interact immediately with (Gomez-Galan, Vazquez-Cano, Rosa, \& Lopez-Meneses, 2020). Furthermore, the immersive scenarios which integrate AR with learning contents, real contexts, and competences from a visual approach, may assist activate students' cognitive learning processes, and simultaneously, foster a more motivating, collaborative, and interactive learning process (Lai, Chen, \& Lee, 2019).

Lastly, AR has also helped students improve their memory (tom Dieck, Jung, \& Rauschnabel, 2018). It has helped them acquire memory-related skills, which are needed to access their learning contents and put them into the real-life practice (Gomez-Galan, VazquezCano, Rosa, \& Lopez-Meneses, 2020). AR has enabled students to remember or recollect more knowledge or clues that were memorized during AR learning activities or tasks than conventional physical classes. Hence, AR experiences have led to an increase in students' capabilities to retain long-term memory (tom Dieck, Jung, \& Rauschnabel, 2018). This, in turn, has enabled students continue to learn, increase their enrolment and retention, and helped to improve student motivation and academic performance. Our research findings, which show that students with good or very good performance (80\%) in their learning with AR tools when compared to their performance $(62.1 \%)$ before AR intervention-are supported by the above academic studies, which previously reported that AR allows for a more attractive learning environment and a better understanding of different school subjects in real-context learning. 
Although AR technology offers many advantages to students, there are also limitations and challenges of integrating AR to student and teacher learning. Mentoring program, for example, is suitable to train teachers to integrate AR in student learning. Mentoring could enable tacit knowledge transfer through informal learning. Mentors or experts transfer their experiences, skills, technical skills and relevant knowledge to their mentees. The concept of mentoring scheme allows schoolteachers receive guidance, advice, and support from experts, also called "knowledge sharing." AR is hereby deemed as sufficient to offer students a sense of completeness in the learning processes, as good quality education has to mix conventional teaching tools with technological means, which then inspires and motivates future instruction.

\section{Conclusion}

The newly developed AR module is an attempt to assist teachers nurture their students through knowledge transfer programs, increase their overall engagement, peer interactions and collaboration, and improve their confidence to be successful learners in the future. Since this is an exploration study into rural primary school students, this research project should be conducted for certain longer periods of study to investigate further impacts of AR intervention on primary school students. More AR tools should be embedded or integrated into multiple school subjects, especially regarding STEM or STEAM learning. In the future, in this project, there is a new collaborator for contributing new and enhanced AR tools for student learning. To be a well-developed country, the exploration to AR technology should be integrated into school learning to increase student awareness with regards to the different components of IR 4.0 and encourage them to equip themselves with $21^{\text {st }}$-century skills, which is in line with the initiatives in the Malaysia Education Blueprint. This social engagement project is also endeavored to enhance student engagement, increase their general education practices, and improve their retention and success rates when in middle school or higher education.

\section{Acknowledgment}

The authors thank the Ministry of Education for the Knowledge Transfer Grant of Malaysia Research University Network (MRUN) Project (MRUN2019-3E). Besides that, the authors would like to acknowledge all co-partners, collaborators, teachers, and students for the participation and assistance in the project conduction and data collection. 


\section{Funding}

This study is funded by Knowledge Transfer Grant of Malaysia Research University Network (MRUN) Project (MRUN2019-3E).

\section{Declaration of Conflicting Interest}

The authors declare that they have no conflict of interest.

\section{Author Contribution}

Zuraidah Abdullah and Seng Yue Wong conceived of the presented idea. Muhamad Saiful Haq Hussin developed the theory and Nahrizul Adib Kadri performed the computations. Unaizah Hanum Obaidellah and Mohd Nashrul Mohd Zubir verified the analytical methods. Zuraidah Abdullah encouraged Seng Yue Wong to investigate AR aspect and supervised the findings of this work. All authors discussed the results and contributed to the final manuscript.

\section{Short Biography}

Dr. Seng Yue Wong (ORCID ID: 0000-0001-9278-4348) is a senior lecturer in Centre for Internship Training and Academic enrichment (CITrA), University of Malaya, Kuala Lumpur, Malaysia. His latest research interests are gamification, MOOC, e-Learning, learning technologies, Game-based Learning, Augmented Reality (AR) / Virtual Reality (VR) games.

Associate Professor Dr. Zuraidah Abdullah (ORCID ID: 0000-0003-3196-1536) is a senior lecturer in Faculty of Education, University of Malaya. Her research is basically focusing on society from the perspective of education such as the issue of Professional Learning Community (PLC) in schools, Inclusive education program, the National School Empowerment based on the PPPM 2013-2025, trans-genders, resiliency of university students and also promoting peace education to secondary level students in order to maintain peaceful and boosting unity.

Associate Professor Dr. Muhammad Saiful Haq Bin Hussin is a senior lecturer in the Department of Malay Language, the Academy of Malay Studies, University of Malaya since August 2007 to date. His expertise is Malay Language (Psycholinguistics), Malay Language Teaching and Jawi Spelling Multimedia Systems. 
Associate Professor Dr. Nahrizul Adib Kadri (ORCID ID: 0000-0001-9694-4337) is a senior lecturer in Faculty of Engineering, University of Malaya. His current research interest is in the area of BioMEMS and lab-on-chip, particularly in the development of low-cost and practical devices for characterization of cell populations and diagnostic applications. He is very much involved with various community engagement programs. From feeding the homeless to tuition classes for underprivileged children, he has teamed up with UM students and a number of NGOs to engage with the community at various levels.

Dr. Unaizah Hanum Binti Obaidellah (ORCID ID: 0000-0003-4822-2174) is a senior lecturer in Faculty of Computer Science and Information Technology, University of Malaya. Her expertise are eye-tracking, cognition and learning, computer programming education, special needs education, and cognitive-behavioral research.

Dr. Mohd Nashrul Mohd Zubir is a senior lecturer in Faculty of Engineering, University of Malaya. His research interest spans from active and passive heat transfer enhancement, nanomaterial synthesis for heat transfer application, to fouling mitigation and desalination system.

\section{References}

Alalwan, N., Cheng, L., Al-Samarraie, H., Yousef, R., Alzahrani, A. I., \& Sarsam, S. M. (2020). Challenges and prospects of virtual reality and augmented reality utilizing among primary school teachers: A developing country perspective. Studies in Educational Evaluation, 66, Article 100876. https://doi.org/10.1016/j.stueduc.2020.100876

Arici, F., Yildirim, P., Caliklar, S., \& Yilmaz, R. M. (2019). Research trends in the use of augmented reality in science education: Content and bibliometric mapping analysis. Computers \& Education, 142, Article 103647.

https://doi.org/10.1016/j.compedu.2019.103647

Bonner, E., \& Reinders, H. (2018). Augmented and Virtual reality in the language classroom: Practical ideas. Teaching English with Technology, 18(3), 33-53.

https://www.ceeol.com/search/article-detail?id=683374

Castaneda, D. I., \& Cuellar, S. (2020). Knowledge sharing and innovation: A systematic review. Knowledge and Process Management, 27, 159-173. 
Chang, S. C., \& Hwang, G. J. (2018). Impacts of an augmented reality-based flipped learning guiding approach on students' scientific project performance and perceptions. Computers \& Education, 125, 226-239. https://doi.org/10.1016/j.compedu.2018.06.007

Cheng, K-H. (2017). Reading an augmented reality book: An exploration of learners' cognitive load, motivation, and attitudes. Australasian Journal of Educational Technology, 33(4), 53-69. https://doi.org/10.14742/ajet.2820

Cheng, K-H. (2018). Surveying students' conceptions of learning science by augmented reality and their scientific epistemic beliefs. Eurasia Journal of Mathematics, Science and Technology Education, 14(4), 1147-1159. https://doi.org/10.29333/ejmste/81811

Cheng, E.C.K. (2020). Knowledge transfer strategies and practices for higher education institutions. VINE Journal of Information and Knowledge Management Systems, 51(2), 288-301. https://doi.org/10.1108/VJIKMS-11-2019-0184

Del Amo, I. F., Erkoyuncu, J. A., Roy, R., Palmarini, R., \& Onoufriou, D. (2018). A systematic review of augmented reality content-related techniques for knowledge transfer in maintenance applications. Computers in Industry, 103, 47-71.

https://doi.org/10.1016/j.compind.2018.08007

Dunwill, E. (2016). Four changes that will shape the classroom of the future: making education fully technological. eLearning Industry. https://elearningindustry.com/4-changes-willshape-classroom-of-the-future-making-education-fully-technological.

Firdaus, R. B. R., Mohamad, O., Mohammad, T., \& Gunaratne, M.S. (2020). Community partnership through knowledge transfer program: Assessment from the perspectives of academic's experience. SAGE Open, 10(4), 1-10.

https://doi.org/10.177/2158244020980742

Georgiou, Y., \& Kyza, E. A. (2018). Relations between student motivation, immersion and learning outcomes in location-based augmented-reality setting. Computers in Human Behavior, 89, 173-181. https://doi.org/10.1016/j.chb.2018.08.011

Gomez-Galan, J., Vazquez-Cano, E., Rosa, A. L. d. 1., \& Lopez-Meneses, E. (2020). SocioEducational impact of Augmented Reality (AR) in sustainable learning ecologies: A semantic modelling approach. Sustainability, 12, Article 9116.

https://doi.org/10.3390/su12219116 
Hincapie, M., Diaz, C., Valencia, A., Contero, M., \& Guemes-Castorena, D. (2021). Educational applications of augmented reality: A bibliometric study. Computers and Electrical Engineering, 93, Article 107289.

\section{https://doi.org/10.1016/j.compeleceng.2021.107289}

Hussin, A. A. (2018). Education 4.0 made simple: Ideas for teaching. International Journal of Education \& Literacy Studies, 6(3), 92-98. http://dx.doi.org/10.7575/aiac.ijels.v.6n.3p.92

Kanchewa, S., Christensen, K.M., Poon, C.Y.S., Parnes, M., \& Schwartz, S. (2021). More than fun and games? Understanding the role of school-based mentor-mentee match activity profiles in relationship processes and outcomes. Children and Youth Services Review, 120, Article 105757. https://doi.org/10.1016/j.childyouth.2020.105757

Kremer, H., Villamor, I., \& Aguinis, H. (2019). Innovation leadership: Best-practice recommendations for promoting employee creativity, voice and knowledge sharing. Business Horizons, 62(1), 65-74. https://doi.org/10.1016/j.bushor.2018.08.010

Lai, A. F., Chen, C. H., \& Lee, G. Y. (2019). An Augmented Reality-based learning approach to enhancing students' science reading performances from the perspectives of the cognitive load theory. British Journal of Educational Technology, 50, 232-247.

\section{https://doi.org/10.1111/bjet.12716}

Lee, K. M., Kraus, S. E., Suandi, T., \& Hamzah, A. (2016). Exploring the contribution of mentoring practices to mentee learning in a Malaysian youth development programme. International Journal of Adolescence and Youth, 21(4), 419-432. https://doi.org/10.1080/02673843.2013.862732

Masood, T., \& Egger, J. (2019). Augmented reality in support of Industry 4.0 -implementation challenges and success factors. Robotics and Computer Integrated Manufacturing, 58, 181195. https://doi.org/10.1016/j.rcim.2019.02.003

Ozdamli, F., \& Karagozlu, D. (2018). Preschool teachers' opinions on the use of augmented reality application in preschool science education. Croatian Journal of Education, 20(1), 43-74. https://doi.org/10.15516/cje.v20i1.2626

Pantelic, A., \& Vukovac, D. P. (2017). The development of educational augmented reality application: A practical approach. Proceedings of ICERI2017 Conference, Seville, Spain, 8745-8752.

Petrov, P. D., \& Atanasova, T. V. (2020). The effect of Augmented Reality on students' learning performance in STEM education. Information, 11(4), 209. 
Salar, R., Arici, F., Caliklar, S., \& Yilmaz, R. M. (2020). A model for Augmented Reality immersion experiences of university students studying in science education. Journal of Science Education and Technology, 29, 257-271. https://doi.org/10.1007/s10956-01909810-X

Sommerauer, P., \& Müller, O. (2018). Augmented Reality for teaching and learning - A literature review on theoretical and empirical foundations. $26^{\text {th }}$ European Conference on Information Systems (ECIS 2018), Portsmouth, UK.

Sumaryanta, Mardapi, D., Sugiman, \& Herawan, T. (2019). Community-based teacher training: Transformation of sustainable teacher empowerment strategy in Indonesia. Journal of Teacher Education for Sustainability, 21(1), 48-66. https://doi.org/10.2478/jtes2019-0004

Tang, Y. (2021). Help first-year college students to learn their library through an augmented reality game. The Journal of Academic Librarianship, 47, Article 102294. https://doi.org/10.1016/j.acalib.2020.102294

tom Dieck, M. C., Jung, T. H., \& Rauschnabel, P. A. (2018). Determining visitor engagement through augmented reality at science festivals: An experience economy perspective. Computers in Human Behavior, 82, 44-53. https://doi.org/10.1016/j.chb.2017.12.043

Vosinakis, S., Anastassakis, G., \& Koutsabasis, P. (2018). Teaching and learning logic programming in virtual worlds using interactive microworld representations. British Journal of Educational Technology, 49(1), 30-44. https://doi.org/10.1111/bjet.12531

Wang, C., Yan, W., Guo, F., Li, Y., \& Yao, M. (2020). Service-learning and Chinese college students' knowledge transfer development. Frontiers in Psychology, 11, Article 606334. https://doi.org/10.3389/fpsyg.2020.606334

Yoon, S., Anderson, E., Lin, J., \& Elinich, K. (2017). How augmented reality enables conceptual understanding of challenging science content. Journal of Educational Technology \& Society, 20(1), 156-168. https://eric.ed.gov/?id=EJ1125896

Yoon, S. A., Anderson, E., Park, M., Elinich, K., \& Lin, J. (2018). How augmented reality, textual, and collaborative scaffolds work synergistically to improve learning in a science museum. Research in Science \& Technological Education, 36(3), 261-281. https://doi.org/10.1080/02635143.2017.1386645

Zanchetta, M. S., Bailey, A., Kolisnyk, O., Baku, L., Schwind, J., Osino, E., ... \& Yu, L. (2017). Mentors' and mentees' intellectual-partnership through the lens of the transformative learning theory. Nurse education in practice, 25, 111-120. 
Zhu, X., Sun, B., \& Luo, Y. (2018). Interactive learning system "ViMis" for scientific visualization course. Interactive Learning Environment, 26(4), 553-565.

https://doi.org/10.1080/10494820.2017.1371197 